\title{
Carcinoma gástrico adenoescamoso - Relato de Caso
}

\author{
Squamous cell carcinoma of the Stomach - Clinical Study \\ Juliana Pascutti Sant'Ana ${ }^{1}$, Juliana do Carmo Fazzolari ${ }^{1}$, Ariel Garcia Jeldes ${ }^{1}$, Eduardo Rullo Maranhão \\ Dias $^{2}$, Tercio De Campos ${ }^{3}$, Paulo Kassab ${ }^{4}$
}

\begin{abstract}
Resumo
O adenocarcinoma gástrico de células escamosas é um tipo histológico raro de neoplasia maligna. A etiopatogenia do desenvolvimento desse tumor ainda não é completamente esclarecida. São menos de 100 casos publicados na literatura que relatam esse tumor como manifestação primária. $O$ prognóstico costuma ser reservado, tanto pela agressividade do tumor quanto pelo diagnóstico tardio. Neste relato, descreve-se o caso de um paciente do sexo masculino de 33 anos, pardo, não tabagista e não etilista, diagnosticado com Adenocarcinoma gástrico escamoso. A Endoscopia Digestiva Alta possibilitou a identificação da lesão neoplásica e realização de biópsias que confirmaram o diagnóstico. O caso segue em investigação quanto à disseminação e identificação de acometimento em demais órgãos.
\end{abstract}

Descritores: Carcinoma adenoescamoso, Neoplasias gástricas, Adenocarcinoma, Carcinoma de células escamosas, Endoscopia gastrointestinal

\section{Abstract}

The squamous cell gastric adenocarcinoma is a rare histologic type of malignant neoplasm. Its development ethiopathogeny is still not completely established. There are less than 100 cases published that describe this kind of tumor as a primary site. Usually the prognoses is not good, due to a late diagnosis and a to its aggressive behavior. In this case report, it's described the case of a 33 years old, non-

1. Acadêmico da Faculdade de Ciências Médicas da Santa Casa de São Paulo - $5^{\circ}$ Ano do Curso de Graduação em Medicina

2. Residente da Irmandade da Santa Casa de Misericórdia de São Paulo-Departamento de Cirurgia

3. Professor Adjunto da Faculdade de Ciências Médicas da Santa Casa de São Paulo - Departamento de Cirurgia

4. Professor Livre Docente da Faculdade de Ciências Médicas da Santa Casa de São Paulo - Departamento de Cirurgia

Trabalho realizado: Faculdade de Ciências Médicas da Santa Casa de São Paulo - Departamento de Cirurgia

Endereço para correspondência: Juliana Pascutti Sant'Ana. Rua Martinico Prado, 242 - Vila Buarque - 01224-011 - São Paulo-SP-Brasil smoker and non-alcoholic man, who has been diagnosed with Gastric Squamous Adenocarcinoma. An Upper Gastrointestinal Endoscopy made possible the detection and biopsy of the lesion, that confirmed the diagnosis. The case is still in investigation as to the dissemination to other structures.

Keywords: Carcinoma, adenosquamous; Stomach neoplasms; Adenocarcinoma; Carcinoma, squamous cell; Endoscopy, gastrointestinal

\section{Introdução}

O adenocarcinoma escamoso do estômago é um tumor raro que apresenta uma incidência entre $0,04 \%$ e $0,07 \%$ dentre os tumores gástricos ${ }^{(1-2)}$. São menos de 100 casos relatados na literatura ${ }^{(3)}$. A relação entre homens e mulheres acometidos é de 4:1 e sua maior frequência ocorre na sexta década de $v i_{a}{ }^{(4)}$. Ocorre com maior prevalência em populações asiáticas $^{(5)}$. O comportamento clínico-patológico do tumor é influenciado basicamente pelo componente adenocarcinomatoso. Esse divide-se em três grupos com características distintas: o indiferenciado, o moderadamente diferenciado e o bem diferenciado. $\mathrm{O}$ indiferenciado aparece em idade mais precoce e se distribui igualmente nos sexos, enquanto o bem diferenciado aparece em idade mais avançada com predomínio no sexo masculino. O bem diferenciado apresenta, com maior frequência, metástases hepáticas via sistema porta e acometimento linfonodal; o indiferenciado desenvolve com mais frequência carcinomatose peritoneal. O moderadamente diferenciado apresenta caracteres intermediários entre os dois grupos anteriores. Para o diagnóstico anatomopatológico é necessário identificar pontes intercelulares e massas de células queratinizadas com a formação de pérolas córneas nas áreas escamosas ${ }^{(5)}$. O prognóstico do carcinoma adenoescamoso é extremamente reservado devido à maior profundidade de invasão e a maior frequência de disseminação linfática e vascular das células carcinomatosas ${ }^{(5)}$. A origem das células escamosas não está bem definida, pode ser que elas estejam relacionadas a áreas de metaplasia epidermóide, em áreas de epitélio escamoso ectópico 
ou de células basais não diferenciadas; sendo que o tabagismo parece ser um fator fortemente associado ${ }^{(6-7)}$.

\section{Relato de Caso}

Homem, 33 anos, pardo, casado, natural de Ilhéus (BA), procedente de Embu das Artes (SP), procurou o serviço da Santa Casa de São Paulo com queixa de dor abdominal, em região mesogástrica, sem irradiação, há 90 dias. Relatava piora importante dos sintomas há 45 dias, associada à enterorragia e melena. Negava fatores de melhora ou piora, náuseas ou vômitos. Referia também perda ponderal de $10 \mathrm{~kg}$ no período. Nega comorbidades, alergias, internações prévias, tabagismo e etilismo.

Ao exame, apresentava-se em bom estado geral, corado, hidratado, acianótico, afebril, anictérico, lúcido e orientado em tempo e espaço. Havia linfonodomegalia cervical, axilar e inguinal. Sem demais alterações no exame físico.

Trouxe uma endoscopia digestiva alta (EDA) realizada em serviço particular há 40 dias, que evidenciava: monilíase esofágica e lesão extensa ulcerada de $4 \mathrm{~cm}$ em corpo gástrico proximal, próximo à cárdia, com bordos elevados, irregulares, com friabilidade importante e convergência de pregas. Apresentando coágulo aderido, medindo cerca de $5 \mathrm{~cm}$ em seu maior eixo. A biópsia gástrica mostrou adenocarcinoma gástrico, ulcerado.

Foi, então, solicitado uma tomografia computadorizada (TC) de tórax, abdômen e pelve e uma nova EDA, além de exames laboratoriais. Na TC tórax, abdômen e pelve evidenciaram-se: linfonodomegalias da cadeia supraclavicular esquerda, linfonodomegalias nas cadeias do ligamento gastrohepático, portocaval, celíacos bilaterais, retrocaval, para-aórtica esquerda, mesentéricos, ilíacas comuns e ilíaca externa direita, medindo até $2,8 \mathrm{~cm}$ no menor eixo no plano axial (ligamento hepático); espessamento parietal irregular de parede posterior do corpo gástrico, sugerindo lesão neoplásica com extensão extramural; pequena quantidade de líquido livre na cavidade peritoneal; fígado de topografia e dimensões normais, apresentando formação nodular hipodensa no segmento II do lobo esquerdo, medindo $1,3 \mathrm{~cm}$.

Na EDA evidenciou-se: lesão úlcero-infiltrativa em parede posterior próximo à cárdia, medindo cerca de $1 \mathrm{~cm}$ com bordas elevadas e enantemáticas, friável ao toque, com fundo sujo de fibrina e necrose (Bormman 3) figura 1. Lesão plana deprimida com mucosa pouco enantemática na $2^{a}$ porção duodenal, medindo cerca de 0,4cm (classificação de Paris 0-2C). Foi realizada biópsia gástrica que evidenciou Carcinoma pouco diferenciado com áreas de aspecto escamoso; biópsia duodenal que evidenciou: infiltração de carcinoma pouco diferenciado, com numerosos êmbolos linfáticos em mucosa duodenal. Pelo estudo imunohistoquímico a amostra era compatível com carcinoma adenoescamoso, sendo que o componente de adenocarcinoma está representado por células pouco coesas em 30\% do material.

Os exames laboratoriais não demonstravam alterações: Hemoglobina $=12,3 \mathrm{~g} / \mathrm{dL}$, leucócitos $=5500 /$ $\mathrm{mm}^{3}$, plaquetas $=282 \mathrm{mil} / \mathrm{mm}^{3}$, TTPA $=30,7$ segundos, INR $=1,28$.

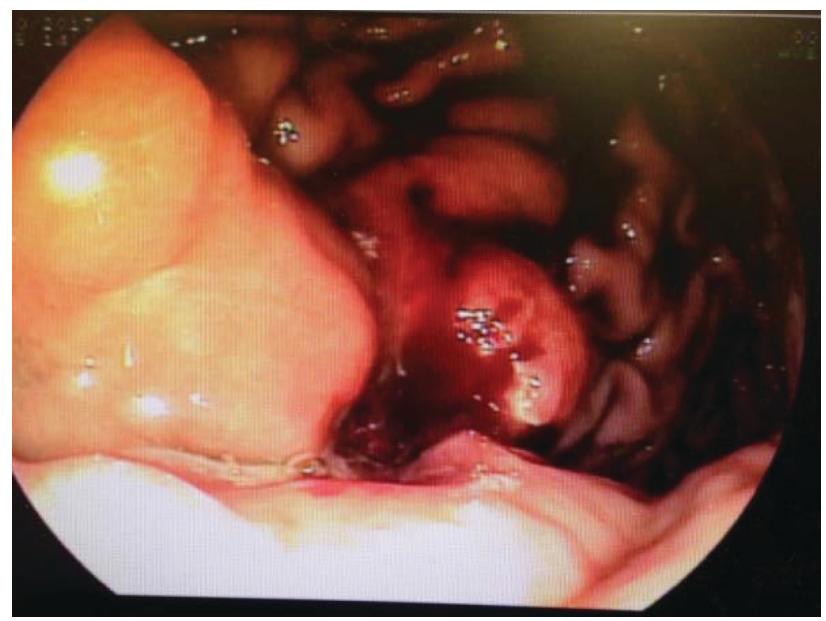

Figura 1 - Endoscopia digestiva alta com lesão úlceroinfiltrativa em parede posterior de estômago.

Devido ao quadro clínico associado aos exames complementares, optou-se pela realização de videolaparoscopia diagnóstica, a fim de estadiar a doença do paciente e definir a melhor conduta para o caso figura 2: No exame foi identificado linfonodomegalia em cadeia perigástrica $4 \mathrm{~B}$ e tumoração palpável em corpo até cárdia sem invasão de serosa. Fígado e diafragma livres de doença. Presença de nódulo único em peritônio, sugestivo de carcinomatose, sem outros implantes em cavidade. Mínima quantidade de líquido livre na cavidade, sendo aspirado $20 \mathrm{ml}$ de líquido citrino - enviado para citologia oncótica. Optou-se devido a isto pelo tratamento oncológico clínico, não sendo indicada a ressecção.

\section{Discussão}

O Adenocarcinoma gástrico do estômago é um tumor raro, com incidência menor que $1 \%$ dentre as neoplasias gástricas malignas, e quando ocorre é mais comumente encontrado na sexta década de vida. Pode ser subdivido, segundo a histologia, como pouco, muito ou moderadamente diferenciado, sendo que o pouco diferenciado apresenta disseminação preferencialmente peritoneal e o muito diferenciado, linfática. O caso descrito evidencia um paciente de 33 


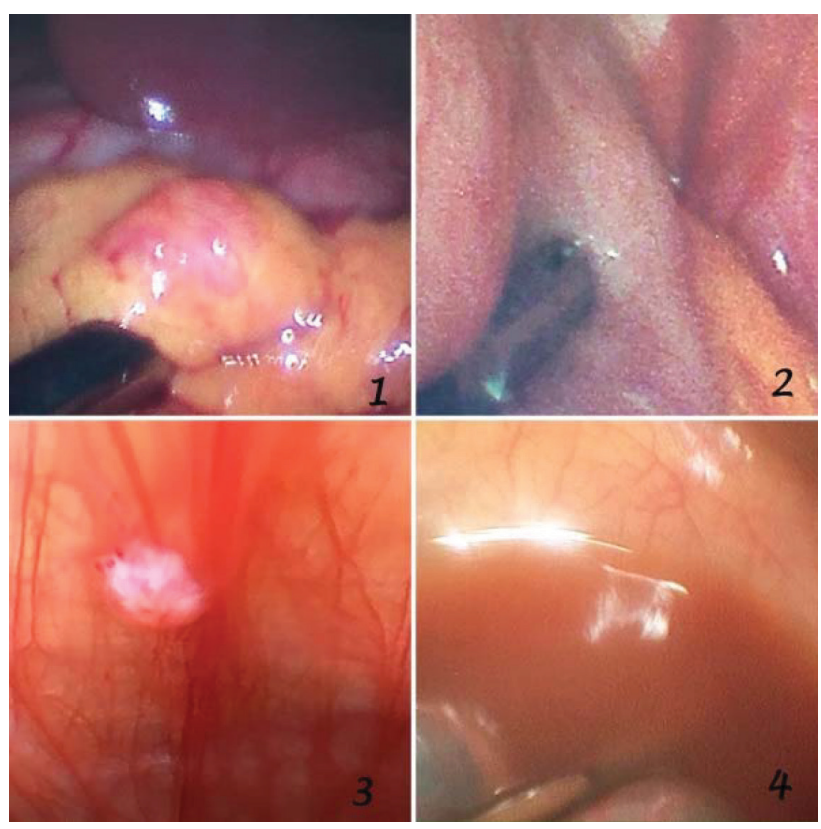

Figura 2 - Videolaparoscopia mostrando nas imagens 1 e 2 linfonodomegalia; imagem 3 - nódulo em peritônio; imagem 4 - líquido livre na cavidade

anos não tabagista sem antecedentes familiares e sem comorbidades, portador de um tumor gástrico do tipo adenoescamoso pouco diferenciado, caracterizado fora do pico de incidência etário, com provável disseminação linfática e peritoneal. Outro fator que chama atenção é a rápida evolução dos sintomas, sendo que o paciente levou cerca de 45 dias entre a piora dos sintomas e acesso ao nosso serviço, característica observada nesse tipo histológico, o qual costuma apresentar um desenvolvimento agressivo. Os achados na videolaparoscopia diagnóstica são sugestivos de doença disseminada, fato comumente relatado nos demais casos, que referem doença disseminada ao diagnóstico. Apesar do prognóstico reservado, as terapias paliativas podem ser um recurso terapêutico na busca da promoção do aumento da sobrevida e melhora da qualidade de vida do paciente.

\section{Conclusão}

Esse relato busca a discussão de um caso de um tipo histológico raro de neoplasia pouco discutido na literatura, manifestado em um paciente jovem. É importante ressaltar que a investigação minuciosa dos sintomas através da história clínica e exame físico é extremamente válida mesmo em pacientes jovens, nos quais devido a menor incidência de neoplasias observa-se menor valorização dos sintomas, o que pode levar a atraso diagnóstico e tratamento inadequado, causando redução da sobrevida.

\section{Referências}

1. Bonnheim DC, Sarac OK, Fett W. Primary squamous cell carcinoma of the stomach. Am J Gastroenterol. 1985; 80(2):91-4.

2. Straus R, Heschel S, Fortmann DJ. Primary adenosquamous carcinoma of the stomach. A case report and review. Cancer. 1969; 24(5):985-95.

3. González-Sánchez JA, Vitón R, Collantes E, Rodríguez-Montes JA. Primary squamous cell carcinoma of the stomach. Clin Med Insights Oncol. 2017; 11:1179554916686076.

4. Schmid CH, Schmid A, Lüttges JE, Kremer B, Henne-Bruns D. Primary squamous cell carcinoma of the stomach. Report of a case and review of the literature. Hepatogastroenterology. 2001; 48(40):1033-6.

5. Manna EDF, Seixas AA, Machado de Araujo RP, Ferro MC. Carcinoma adenoescamoso primário do estômago. Rev Assoc Méd Bras. 1998. 44(2):152-4.

6. Kawabe K, Nakanuma Y, Terada T, Nakamura Y. Adenosquamous carcinoma of the stomach presenting giant gastric folds. Gastroenterol Jpn. 1990; 25(6):739-45.

7. Chen Y, Zhu H, Xu F, Cao Y, Gu X, Wan Y, et al. Clinicopathological characteristics, treatment, and prognosis of 21 patients with primary gastric squamous cell carcinoma. Gastroenterol Res Pract. 2016; 2016:3062547.

Trabalho recebido: 06/12/2017

Trabalho aprovado: 19/05/2018 